\title{
ANALISIS PERHITUNGAN LAJU EROSI DI DAS PULAU TIMOR SEBAGAI ARAHAN PEMANFAATAN LAHAN YANG BERBASIS SUMBER DAYA AIR SECARA TERPADU
}

\author{
Oleh: \\ Sutirto, ST.MT \\ Staf Pengajar Jurusan Teknik Sipil Politeknik Negeri Kupang \\ sutirtojatayu@g.mail.com
}

\begin{abstract}
Abstrak
Bentuk penelitian dan kajian ini merupakan studi kasus dengan mengambil lokasi pada DAS Oesapa Besar Kupang Provinsi Nusa Tenggara Timur. DAS Oesapa Besar termasuk dalam DAS Benain Noelmina yang menjadi wilayah BPDAS Kupang memiliki luas total keseluruhan 46.017.500 $\mathrm{m}^{2}$ atau 4.601,75 Ha didalamnya terdiri atas Sub - Sub DAS sebanyak 74 (tujuh puluh empat) Sub DAS. Wilayah ini termasuk prioritas pertama, karena wilayah tersebut mengalami erosi berat yang sangat luas untuk itu perlunya dikendalikan dan direhabilitasi. Hasil analisa existing DAS Oesapa Besar pada tahun 2009 mempunyai laju erosi 425,771 ton/ha/tahun dan total besarnya erosi 53.662,426 ton/tahun dengan ketebalan erosi lahan 5,6 $\mathrm{mm} /$ tahun. Tingkat bahaya erosi dan kekritisan lahan dengan kreteria Sangat ringan 1.901,86 Ha (41,33), Sedang 1,524,79 Ha (33,13\%), Berat 601,41 Ha (13,07\%) dan Sangat Berat seluas $573,70 \mathrm{Ha}(12,47 \%)$.

Arahan sesuai hasil analisa diperlukan pemanfaatan lahan yang berbasis sumber daya air secara terpadu melalui perlakuan vegetasi dan civil teknis
\end{abstract}

Kata Kunci : Prioritas Pertama, Laju Erosi, Perlakuan Vegetasi dan Civil Teknis.

\section{A. Latar Belakang dan Permasalahan}

Pendayagunaan sumber daya alam dengan mengeksploitasi atau pemanfaatan secara berlebihan, menimbulkan perubahanperubahan dalam ekosistem (lingkungan). Terjadinya lahan kritis disebabkan oleh pemanfaatan dan pendayagunaan lahan yang belum memperhatikan usaha pengawetan tanah, seperti penggunaan lahan yang melebihi kemampuan tanah. (Anonymous, 1987).

Hal tersebut seiring dengan banyaknya Daerah Aliran Sungai (DAS) di Indonesia dengan kondisi kritis. Departemen Kehutanan (Dephut) mengindikasikan kondisi DAS di Indonesia pada umumnya sudah mengalami kerusakan berat sampai sangat berat. Berdasarkan hasil identifikasi Dephut (1999), tercatat 458 DAS kritis di Indonesia terdiri dari 60 DAS termasuk kategori rusak berat sampai sangat berat (16 DAS berada di Pulau Jawa), 222 DAS termasuk kelas sedang sampai berat dan 176 DAS potensial rusak. Jumlah DAS yang telah mengalami kerusakan tersebut saat ini kondisinya tidak semakin membaik, akan tetapi cenderung semakin bertambah, hal ini dibuktikan dengan meningkatnya kejadian bencana alam tanah longsor, banjir dan kekeringan. Laporan dari pihak terkait mengenai upaya rehabilitasi DAS telah banyak dilakukan, tetapi hasilnya belum significant. Sementara bencana alam tanah longsor, banjir, dan kekeringan terjadi semakin meningkat setiap tahunnya. Bahkan terjadi di beberapa wilayah DAS yang biasanya tidak terjadi bencana banjir dan tanah longsor tetapi beberapa tahun terakhir ini malah terjadi, hal ini merupakan indikasi bahwa kondisi DAS di beberapa daerah telah terjadi peningkatan kerusakan (Siaran Pers 
Nomor : S. 596 /PIK-1/2008, 2008 : www.dephut.go.id).

Di Pulau Timor terdapat sebaran DAS yang meliputi Noelmina Kupang, Noelmina TTS, Benain Belu, Benain TTS dan Benain TTU. Hasil analisis prioritas dan sebaran tingkat erosi MMF, erosi sangat ringan $<15$ ton/ha/th terluas pada wilayah Benain TTU ( 913.737,6 ha) dan paling sedikit pada wilayah Noelmina Kupang ( $37.483,5 \mathrm{Ha}$ ). Erosi ringan ( 15-60 ton/ha/th) terluas pada daerah Noelmina Kupang (30.485,5 ha). Erosi yang sedang (60180 ton/ha/th) terluas pada Sub Das Noelmina Kupang ( 8.799 ha) dan tersempit pada Sub Das Benain Belu ( 6.300,8 ha). Selanjutnya erosi berat ( $180-480$ ton/ha/th) terluas di Noelmina TTS $(5.538,4)$ dan tersempit di Benain Belu ( 1.495,4 ha). Erosi tertinggi terjadi pada tingkat erosi ringan yaitu kurang dari 15 ton/ha/th.

DAS Benain Noelmina yang menjadi wilayah BPDAS Kupang memiliki luas 213.357,9 Ha dengan penutupan lahan berupa hutan alam dengan tanaman cemara, ampupu, giricidae, akasia, dengan sebagian semak belukar untuk daerah yang diterlentarkan. Beberapa daerah juga merupakan tanaman tegalan dan sawah irigasi dan tadah hujan.

Walaupun luas areal yang terorosi di Noelmina Kupang tidak begitu luas namun wilayah tersebut termasuk pada prioritas pertama, karena wilayah tersebut mengalami erosi berat yang sangat luas ( Harjadi, Jurnal Ilmu Teknik dan Lingkungan Vol 7 No. 2, 2007)

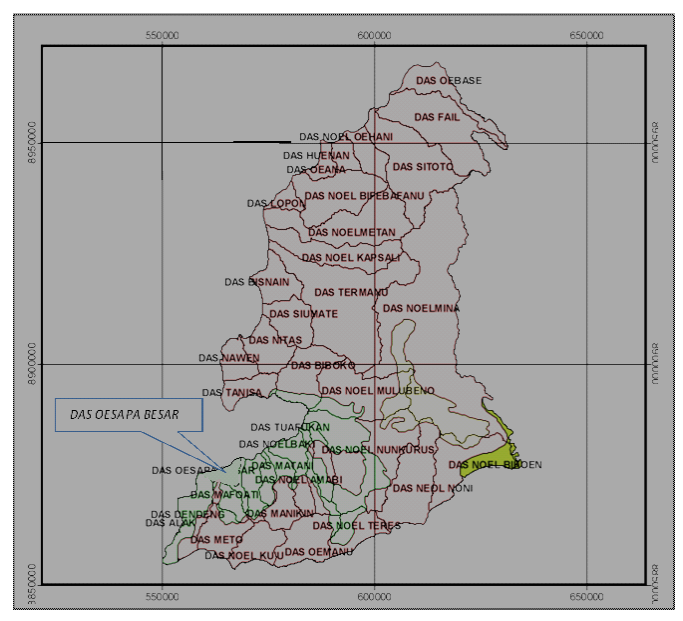

\section{Gambar 1. Peta Sebaran DAS di Pulau Timor}

Melihat berbagai masalah tersebut diatas seperti permasalahan lingkungan dan ketersediaan lahan, serta tingkat erosi lahan yang tinggi diperlukan kajian upaya perhitungan laju erosi yang terjadi di Daerah Aliran Sungai (DAS) sebagai arahan penggunaan lahan yang berbasis sumber daya air secara terpadu (Integrated Water Resources Management) dengan tujuan kelestarian daerah tangkapan air yang dapat terjaga, serta mencegah kerusakan ekosistem dan bencana alam yang lebih besar.

\section{B. Lokasi Kajian}

Untuk mewakili DAS yang berada di Pulau Timor kajian ini mengambil sampel kajian yang berlokasi di DAS Oesapa Besar yang terletak dalam dua Wilayah yaitu Kota Kupang dan Kabupaten Kupang Propinsi Nusa Tenggara Timur dengan memiliki batasbatas wilayah administrasi sebagai berikut :

- Sebelah Utara : Teluk Kupang

- Sebelah Selatan : Laut Timor

- Sebelah Timur : Kab Timor Tengah Selatan ( TTS)

- Sebelah Barat : Selat Semau Adapun lokasi kajian yang termasuk dalam DAS Oesapa Besar meliputi Kecamatan :

- Di bagian hilir dalam wilayah Kecamatan Kelapa Lima dan Kecamatan Oebobo Kota Kupang.

- Di bagian tengah dalam wilayah Kecamatan Maulafa Kota Kupang dan di Kecamatan Taebenu Kabupaten Kupang.

Di bagian hulu dalam wilayah Kecamatan Taebe nu dan Kecamatan Nekmese Kab. Kupang

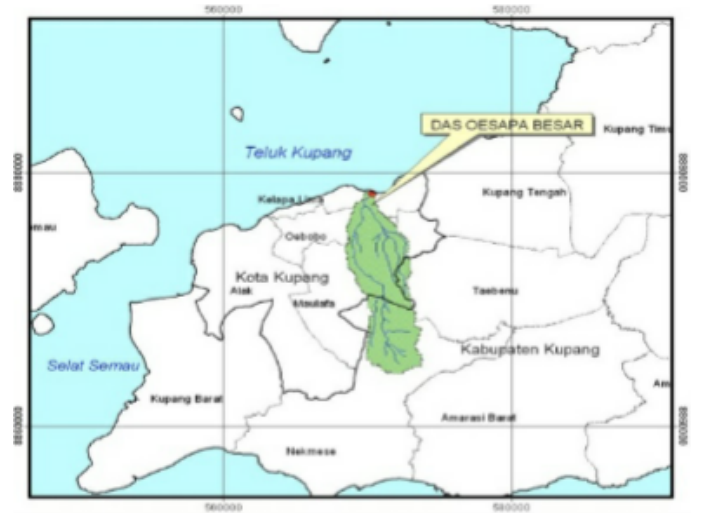




\section{Kondisi Hidrografis}

Gambar 2. Peta Lokasi Kajian

Wilayah kajian beriklim tropis yang mempunyai sifat lembab dan berangin. Berdasarkan letak geografis wilayah mempunyai iklim yang tidak stabil. Setiap tahunnya angin berembus sangat kencang dan tiupan angin timur, sering terjadi erosi angin, kecepatan rata-rata mencapai 13-18 $\mathrm{km} / \mathrm{jam}$, kadang-kadang kecepatan angin rata -rata mencapai $36-44 \mathrm{~km} / \mathrm{jam}$. Angin yang sangat kencang ini terjadi 3 - 5 kali dalam setahun yang disebabkan oleh siklus tropis. Angin ini merupakan satu-satunya terdapat di Indonseia bertiup dari arah Timur Laut kearah Barat Laut sepanjang pantai utara dan pantai selatan.

Faktor iklim lainnya adalah kelembaban, kelembaban umumnya tinggi dengan variasi yang menyolok, musim kemarau kelembaban udara rendah sekitar 40 $\%-50 \%$ sering terjadi.

Langit kurang berawan, khususnya musim kemarau daerah ini menerima radiasi matahari yang sangat tinggi, temperatur yang tinggi dan kelembaban yang rendah menyebabkan evaporasitinggi.

Wilayah kajian beriklim kering yang dipengaruhi oleh angin muson dengan musim hujan yang pendek, sekitar bulan November sampai dengan Maret, dengan suhu udara mulai dari $20,16^{\circ} \mathrm{C}-31^{\circ} \mathrm{C}$. Musim kering sekitar bulan April sampai bulan Oktober dengan suhu udara mulai dari $29,1^{\circ} \mathrm{C}-33,4^{0}$ C. Dari data lapangan diperoleh bahwa kondisi curah hujan hanya berkisar antara 77 $500 \mathrm{~mm}$ per tahun. Hampir sebagian lahan terdiri dari padang rumput, pohon lontar, pohon kelapa, pohon jati dan pohon gewang.

Kelembaban relatif rata- rata bulanan tertinggi terjadi pada bulan Februari sebesar $86,8 \%$ dan terendah terjadi pada bulan September sebesa $61,8 \%$, kecepatan angin rata- rata bulan tertinggi terjadi pada bulan Juli sebesar $5,20 \mathrm{~m} /$ detik, dan terendah terjadi pada bulan Maret sebesar 2,48 m/detik. Penyinaran matahari rata-rata bulanan tertinggi terjadi pada bulan Agustus selama 6,08 jam dan terendah terjadi pada bulan Februari yaitu selama 4,80 jam. Menurut pembagian iklim dari daerah studi termasuk tipe iklim 1 (Tropical Rainy Climates)

\section{Kondisi Topografis}

Secara topograsfis wilayah kajian sebagian besar berada pada ketinggian 10 $50 \mathrm{~m} \mathrm{dpl}$ (diatas permukaan laut), sedangkan bagian utaranya (meliputi sebagian besar Kecamatan Alak dan Kelapa Lima) ketinggiannya berkisar antara $0-10 \mathrm{~m} \mathrm{dpl}$. Selain itu pula di Kota Kupang juga terdapat daerah yang mempunyai ketinggian $>50 \mathrm{~m}$ dpl yaitu pada bagian selatan Kecamatan Maulafa, Oebobo, dan sebagian Kecamatan Kelapa Lima Kecamatan Nekmese dan Kecamtan Amarasi yang meliputi Kelurahankelurahan Kolhua, Sikumana, Penfui, Fatubesi dan Amarasi. Permukaan tanah terdiri dari batu karang dan tidak rata serta tanah berwarna merah dan putih. Dilihat dari kemiringan tanahnya, sebagaian besar mempunyai tingkat kemiringan lahan 0 - $30 \%$ dan sebagian kecil kemiringan lahan antara 3 - 8\%. Sebagian hilir DAS Oesapa Besar mempunyai kemiringan lereng $<5^{\circ}$.

\section{E. Kondisi Jenis Tanah}

Berdasarkan keadaan batuannya di Kota Kupang dan Kabupaten Kupang terdapat kelompok jenis tanah dominan yaitu Alluvial, Grumosol, Litosol, Mediteran Merah Kuning dan Kompleks dengan tesktur tanah halus sampai kasar.

\section{F. Kondisi Penggunaan Lahan}

BP DAS Benain Noelmina, 2010, DAS Oesapa Besar memiliki luas wilayah $4.601,750 \mathrm{Ha}$, dengan pemanfatan lahan akhir pada tahun 2009 sebagai berikut :
a) Hutan Rawa
$=10.148,00 \mathrm{Ha}$
b) Kebun
$=287.170,00 \mathrm{Ha}$
c) Permukiman
$=205.528,00 \mathrm{Ha}$
d) Rumput/tanah kosong
$=595.425,00 \mathrm{Ha}$
e) Sawah tadah hujan
$=17.608,00 \mathrm{Ha}$
f) Semak Belukar
g) Tegalan / ladang
$=3.205 .496,00 \mathrm{Ha}$
$=191.625,00 \mathrm{Ha}$

\section{G. Kondisi Kependudukan}

Berdasarkan hasil Sensus Penduduk 
tahun 2010, penduduk Kota Kupang berjumlah 335.585 jiwa yang terbagi atas 4 Kecamatan dan Kabupaten Kupang 303.908 jiwa yang terbagi atas 24 Kecamatan

\section{H. Perhitungan Debit Limpasan}

Perhitungan dan penentuan besarnya Debit Limpasan Permukaan metode rasional modifikasi dengan cara analisa spasial tumpang susun (overlay) dengan menggunakan perangkat lunak ArcView GIS 3.3. Analisa ini dilakukan dengan mengaktifkan extension Geoproces sing pada perangkat lunak ArcView G/S 3.3. Data-data yang digunakan adalah peta sub-Sub DAS Oesapa Besar (Koef CS dan I), peta tata guna lahan (Koefisien C). Hasil overlay sebaran Debit Limpasan Permukaan dengan kondisi tata guna lahan eksisiting di Sub DAS Oesapa Besar dapat dilihat pada Tabel 1 dan peng gambaran nya pada Gambar Gambar 3 sd. 6 .

Tabel 1 Perhitungan Debit Limpasan DAS

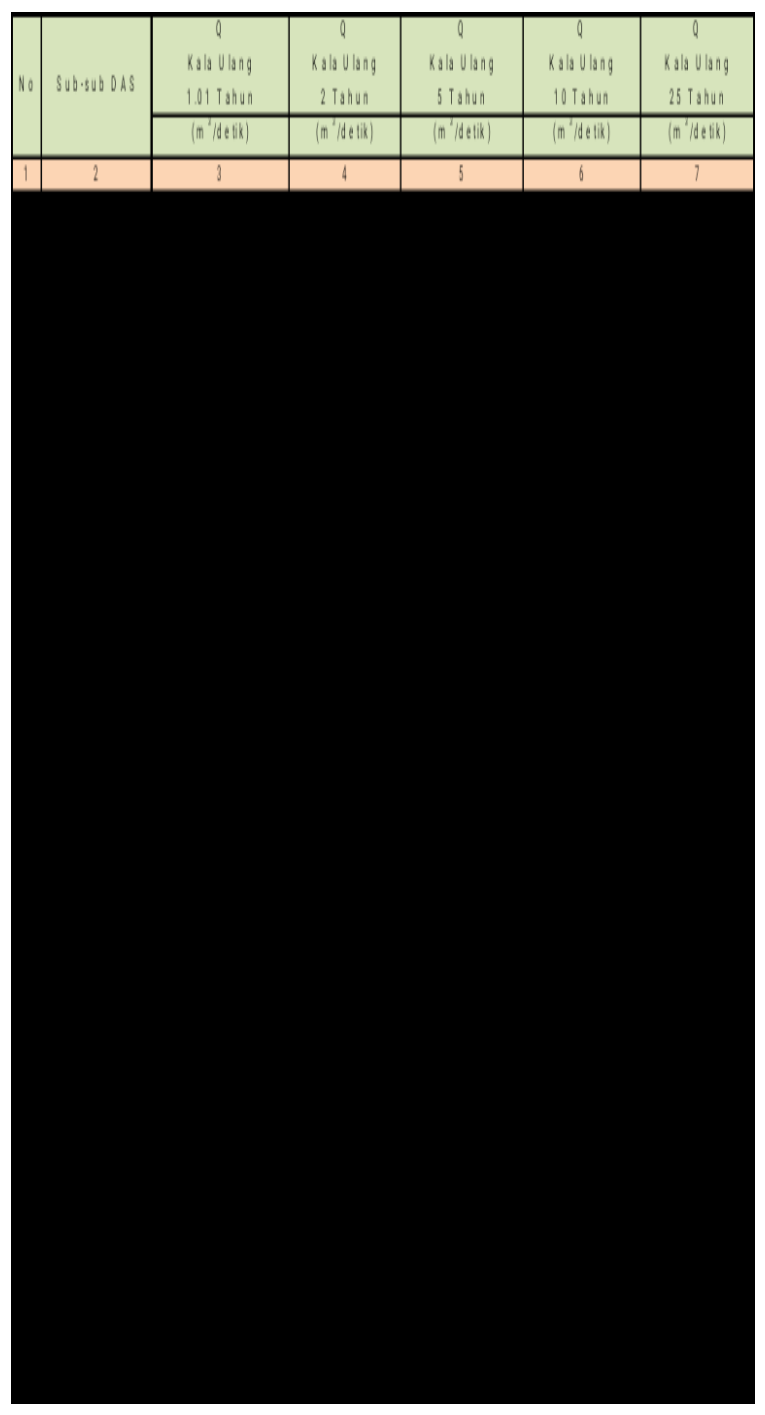

Sumber : Hasil Perhitungan 


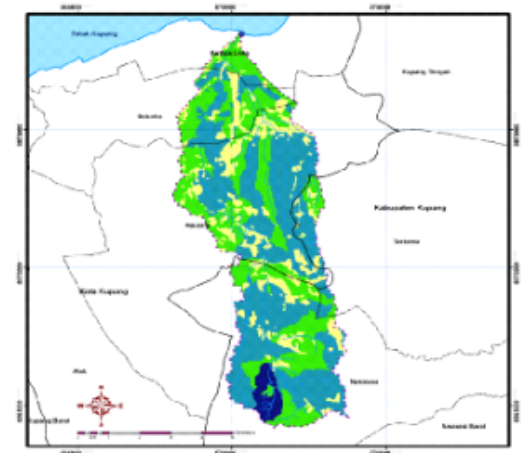

Gambar 3 Peta Debit Limpasan Permukaan Q 1 Tahun

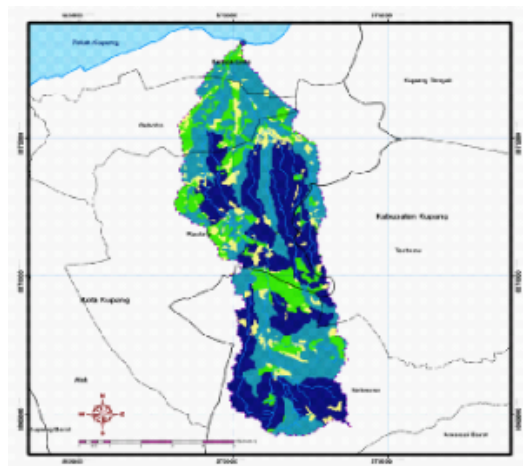

Gambar 4 Peta Debit Limpasan Permukaan Q 5 Tahun

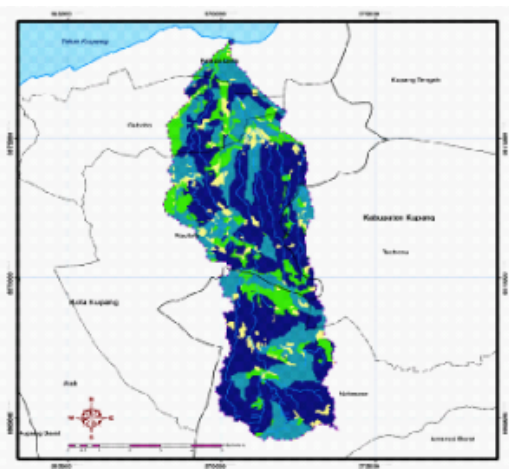

Gambar 5. Peta Debit Limpasan Permukaan $\mathrm{Q}_{10}$ Tahun

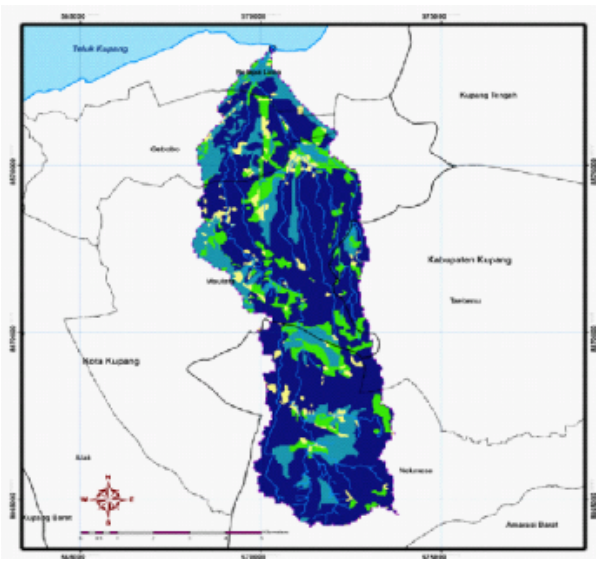

Gambar 6 . Peta Debit Limpasan Permukaan $\mathrm{Q}_{25}$ Tahun

\section{Analisa Laju Erosi dan Penggambaran Peta DAS Oesapa Besar}

Pada daerah aliran cukup luas, proses erosi selalui disertai dengan pengendapan dalam proses pengangkutan. hasil endapan tersebut dipengaruhi oleh besar kecilnya limpasan permukaan. Oleh karena itu Williams (1975) dalam Utomo, 1994:154 mengadakan modifikasi Persamaan Umum Kehilangan Tanah (PUKT) untuk menduga hasil endapan dari setiap kejadian limpasan permukaan dengan mengganti indeks erosivitas hujan dengan erosivitas limpasan permukaan (Rw) dengan rumus : $R w=9,05$. (Vo. Qp) $)^{0,56}$

Dari perhitungan akan didapatkan nilai Rw pada 12 bulan selama 10 tahun pada tiaptiap Sub DAS. Nilai Rw ini kemudian akan digunakan untuk perhitungan erosi dengan rumus MUSLE.

Dari rumus MUSLE dapat diketahui dan dilakukan penggambaran yang dilakukan dengan cara menggabungkan/overlay dari gambar-gambar yang telah dibuat sebelumnya, yaitu gambar debit limpasan permukaan, gambar jenis tanah, gambar faktor tata guna lahan dan penambahan atribut dari hasil perhitungan Rw atau indeks erosivitas limpasan permukaan. Hasil Perhitungan pada Tabel 2 sd 5 sedangkan hasil penggambarannya dapat di lihat pada Gambar 7

Hasil perhitungannya disajikan pada Tabel 2 berikut :

Tabel 2 Perhitungan Harga Ro DAS OesapaBesar

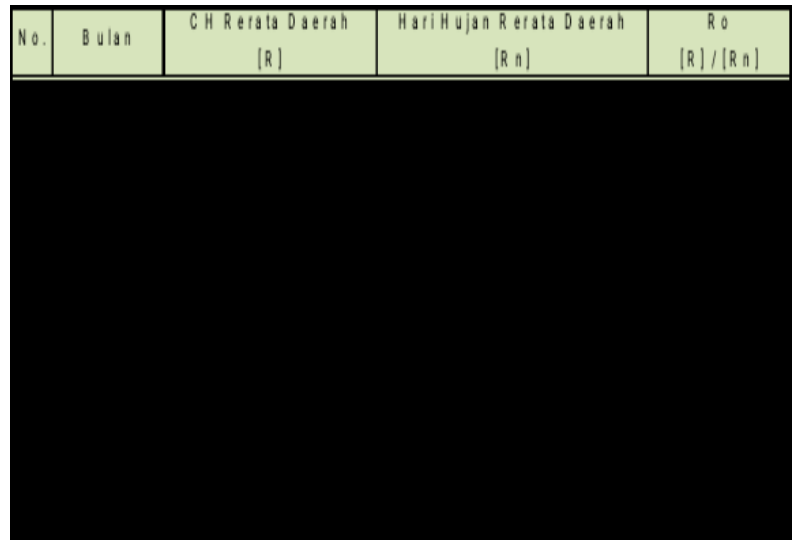


Sumber : Hasil Perhitungan

Tabel 3 Harga MS, $\rho b$ dan RD Pada Tekstur Tanah di DA: Oesapa Besar

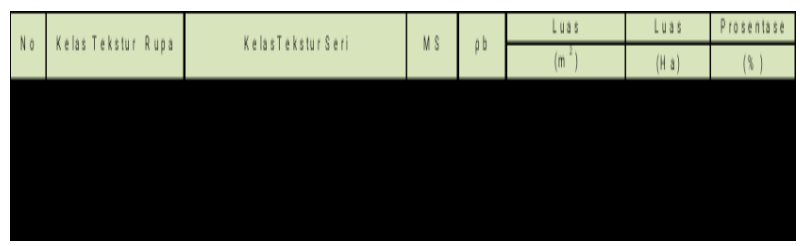

Sumber : Hasil Perhitungan

Tabel 5 Perhitungan Laju Erosi DAS Oesapa Besar

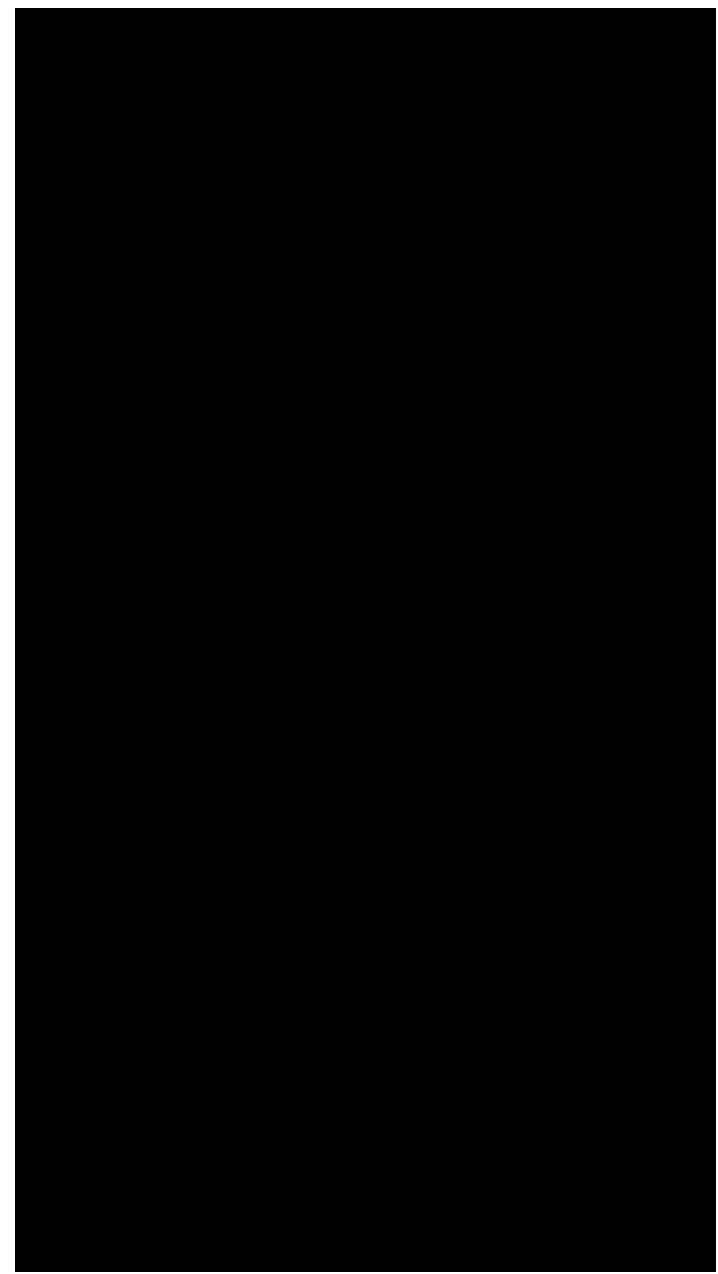

Sumber : Hasil Perhitungan

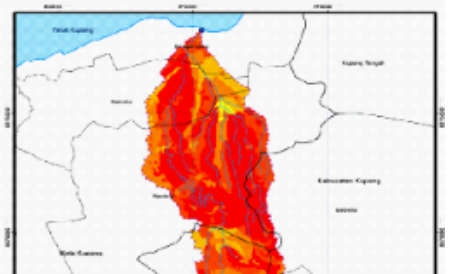


Gambar 8 Prosentase Tingkat Bahaya Erosi DAS Oesapa Besar

Gambar 7. Peta Sebaran Laju Erosi DAS Oesapa Besar

\section{J. Indeks Bahaya Erosi (IBE) dan Tingkat} Kekritisan Lahan

Penentuan Indeks Bahaya Erosi dengan menggunakan metode Hammer. Untuk penentuan tingkat kekritisan lahan dilakukan dengan cara mengelompokkan indeks bahaya erosi kedalam 5 kelompok Hasil penentuan Indeks Bahaya Erosi dapat dilihat pada tabel 6 , sedangkan prosentase tingkat Bahaya Erosi DAS Oesapa Besar dapat di lihat pada Gambar 8

Tabel 6 Tingkat Bahaya Erosi DAS Oesapa Besar

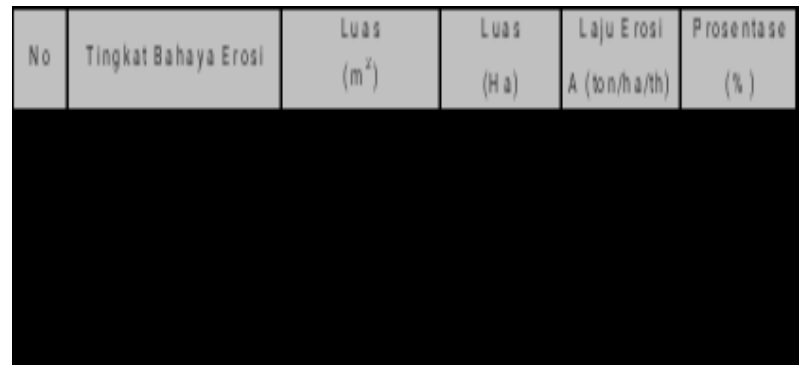

Sumber : Hasil Perhitungan

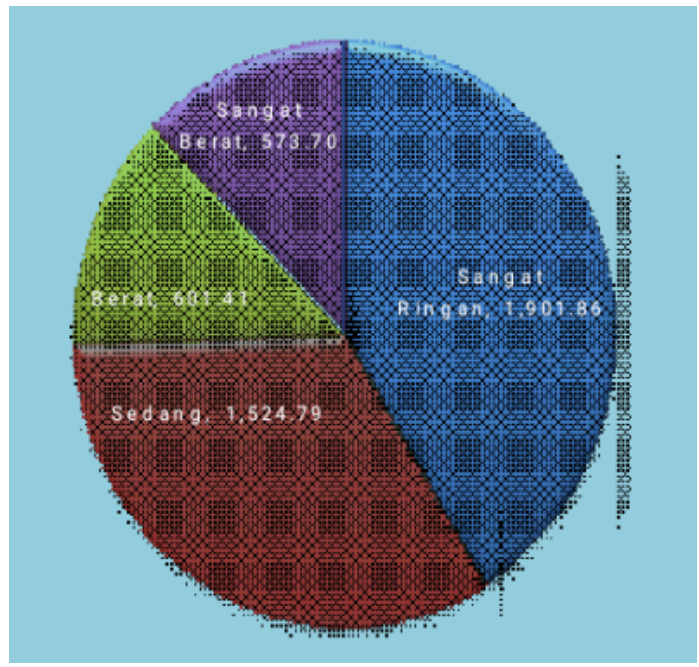

K. Perhitungan Ketebalan Erosi Lahan di DAS Oesapa Besar

Dengan luas $46,02 \mathrm{~km}^{2}$ maka nilai SDR $=15,896 \%$ ( dengan cara interpolasi), total laju erosi di Sub DAS Oesapa Besar sebesar $(A)=425.771$ ton/ha/tahun ( Hasil perhitungan pada Tabel 5)

Total load $($ sedimen $)=$

$$
A \times S D R=425,771 \times 5,896 \%
$$

$=$

ton/ha/tahun

Sesuai hasil perhitungan yang telah diuraikan diatas di DAS Oesapa Besar sebagai berikut :

- Erosi lahan (E) yang terjadi di DAS Oesapa Besar sebesar $=425,771$ ton $/$ ha $/$ tahun .

- Total load (sedimen) = 67,681 ton/ha/tahun

- $\quad$ BD material erosi $=1,2$ Jadi ketebalan Erosi di lahan

$$
\begin{aligned}
=67,681 / 1,2 & =56,40 \mathrm{~m}^{3} / \mathrm{ha} / \text { tahun } \\
& =0,00564 \mathrm{~m} / \text { tahun } \\
& =0,564 \mathrm{Cm} / \text { tahun }
\end{aligned}
$$

L. Arahan Penggunaan Lahan yang Berbasis Sumber Daya Air Secara Terpadu

Untuk memperkecil laju limpasan dan Erosi lahan yang terjadi pada Daerah Aliran Sungai (DAS) di Pulau Timor arahan penggunaan lahan yang berbasis sumber daya air secara terpadu (Integrated Water Resources Management) dengan tujuan kelestarian daerah tangkapan air supaya dapat terjaga, serta mencegah kerusakan ekosistem dan bencana alam yang lebih besar merekomendasikan adanya perlakuanperlakuan melalui Metode Vegetatif dan Civil Teknis di bagian hulu ( Pegunungan ) antara lain:

\section{a. Metode Vegetatif}

Metode vegetatif memanfaatkan bagian-bagian dari tanaman untuk menahan air hujan agar tidak langsung mengenai tanah misalnya daun, batang dan ranting. Selain itu 
akar tanaman juga berfungsi untuk memperbesar kapasitas infiltrasi tanah.

\section{b. Metode Mekanik (Sipil Teknis)}

Usaha konservasi dengan mekanik bertujuan untuk memperkecil laju limpasan permukaan, sehingga daya rusaknya berkurang untuk menampung limpasan permukaan kemudian mengalirkannya melalui bangunan atau saluran yang telah dipersiapkan. Ada beberapa metode yang dapat digunakan (Utomo, 1994 : 85) :

1. Pembuatan Saluran Pemisah. Saluran ini berfungsi agar limpasan permukaan dari lahan atas tidak masuk ke lahan, kemudian limpasan tersebut dialirkan melalui jalan air (Utomo,1989:85).

2. Saluran Pembuang Air (SPA). Saluran pembuang air adalah saluran pembuang untuk menampung dan mengalirkan limpasan permukaan. Saluran ini dibangun searah lereng. Agar dasar saluran tidak terkikis, maka dasar saluran dilengkapi dengan pasangan batu-batuan atau dengan vegetatif linning (Utomo, 1989: 89).

3. Pembuatan teras. Pembuatan teras dimaksudkan untuk mengurangi panjang dan kemiringan lereng, sehingga dapat memperkecil limpasan permukaan. Berdasarkan bentuk dan fungsinya ada beberapa macam teras, yaitu (Utomo, 1989: 86):

- Teras Saluran (channel terrace).

Teras saluran dibangun untuk mengumpulkan air aliran permukaan pada saluran yang telah dipersiapkan, kemudian dialirkan ke jalan air. Teras ini dibuat searah lereng dengan membuat tanggul dengan saluran diatasnya. Tanah untuk tanggul diambil dari sisi atas atau dari kedua sisi tanggul. Ada tiga macam teras saluran:

(a) Teras Datar. Teras datar digunakan untuk tanah dengan kemiringan kurang dari $3 \%$ dan untuk tanah dengan permeabilitas tinggi dan jenis tanah yang kering.

(b) Teras Kredit. Teras ini digunakar untuk tanah dengan kemiringan 3-1c
\% dengan jarak antar guludan bervariasi 5-12 m.

(c) Teras Guludan. Teras guludan digunakan untuk tanah yang lebih peka terhadap erosi guludan ini terbagi menjadi :

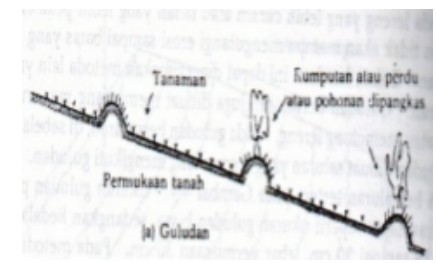

Gambar 9 Teras Guludan (teras kredit)

Persyaratan guludan ( teras kredit ) :

- Tumpukan tanah yang dibuat memanjang menurut arah kontur (memotong lereng).

- Tinggi tumpukan dan lebar dasar dibuat sekitar $25-30 \mathrm{~cm}$.

- Jarak antar guludan tergantung kecuraman lereng (3- 10\%), kepekaan erosi tanah dan erosivitas hujan.

- Guludan diperkuat dengan rumput atau pohon perdu (rendah).

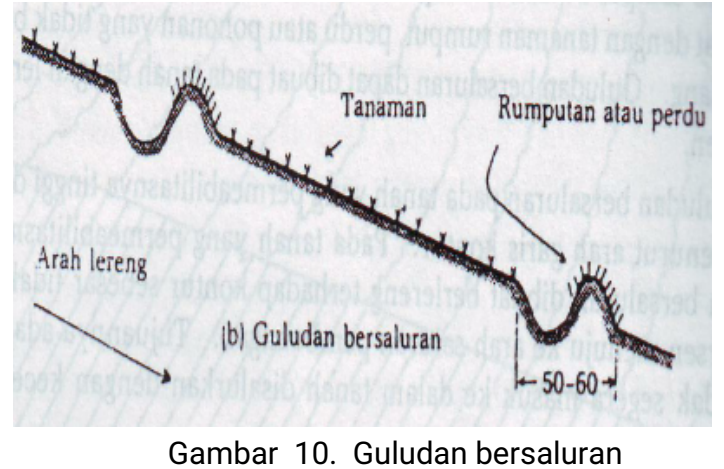

Persyaratan guludan bersaluran :

- Pada lereng yang lebih curam (6\% $12 \%)$ atau tanah yang lebih peka terhadap erosi.

- Dibangun memanjang searah kontur, 
dengan saluran di bagian lereng atas sepanjang guludan.

- Ukuran guludan sama dengan guludan biasa. Kedalaman saluran $25-30 \mathrm{~cm}$ dan lebar atas saluran $30 \mathrm{~cm}$.

- Guludan diperkuat rumput dan pohon perdu.

- Saluran dibuat dengan kemiringan 1\% ke arah saluran pembuangan, agar air yang tidak meresap dapat segera dibuang.

- Teras Bangku atau Tangga (Bench Terrace)

Teras bangku dimaksudkan untuk mengurangi panjang lereng, dengan jalan memotong lereng dan meratakan tanah di bawahnya, sehingga terbentuk deretan bangku atau tangga. Teras bangku dibangun pada tanah dengan kemiringan antara $20-30 \%$ dan mempunyai solum tanah yang cukup dalam. Ada berbagai macam teras bangku yang dapat ditemukan di lapangan:

(a) Teras Bangku Datar (Level Terrace)

(b) Teras Bangku Miring (Slope Terrace)

(c) Teras Bangku Berlawanan Lereng atau Teras Tajam (Steep Terrace)

(d) Teras Pengairan (Irrigation Terrace). Dibangun dengan cara membuat tanggul di ujung teras agar air dapat tersimnan di teras tersebut.

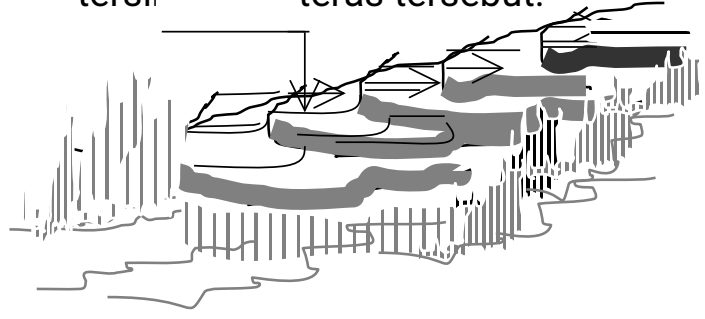

Gambar 11. Penampang Teras Bangku ( Tangga )

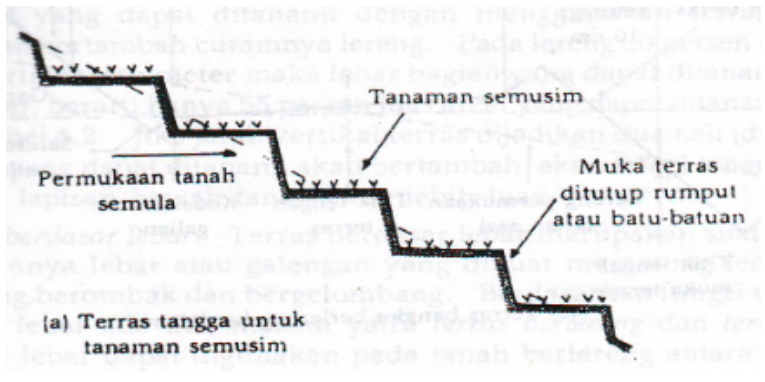

Gambar 12 Teras tangga untuk tanaman semusim

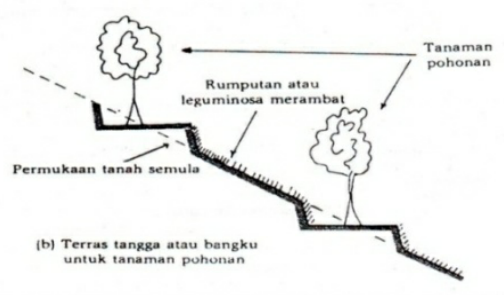

Gambar 13 Teras tangga untuk tanaman

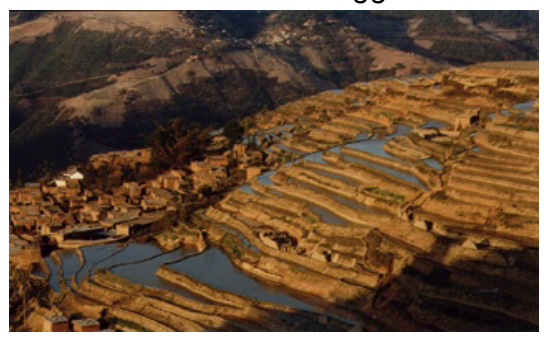

Gambar 14. Teras Bangku ( tangga )yang di terapkan di Indonesia

- Parit Jebakan

Suatu system penangkapan air yang di buat atau di gali memanjang dengan searah garis kontour pada daerah lereng atau perbukitan dengan kemiringan lereng berkisar antara 5 $20 \%$ untuk menjebak aliran air permukaan guna mengurangi laju aliran permukaan (runoff). Prinsip pembuatan parit ini adalah dibuat pada suatu bidang tanah dimana aliran air permukaan akan selalu menuju pada titik terendah di bidang tanah tersebut

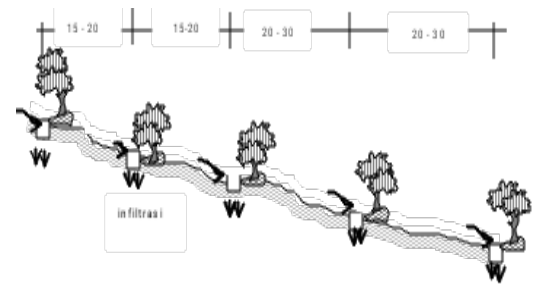


Gambar 15. Kontruksi Parit Jebakan Air

- Rorak

Suatu kontruksi yang di buat untuk menjebak air dengan menggali tanah pada tempat - tempat tertentu di daerah lereng dengan berdemensi segi empat yang berfungsi untuk menguranqi aliran permukaan ( run off)

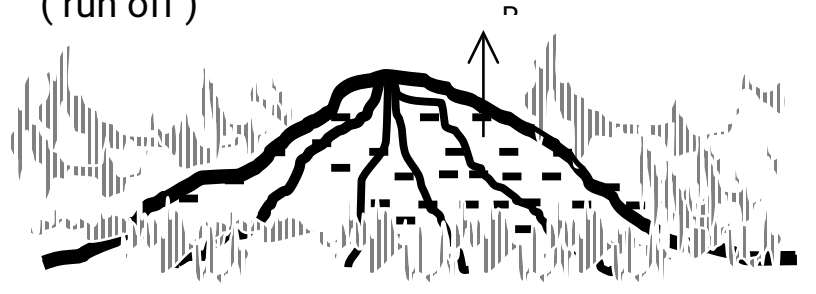

Gambar 16. Perletakan Rorak pada lereng

- Gully Stabilition (Gully Plug).

Suatu system penangkapan air dengan cara membuat suatu bangunan dari kayu papan, bambu atau batu di daerah terjunan alur - alur sungai untuk memperlambat aliran air di lekukan lereng / bukit.

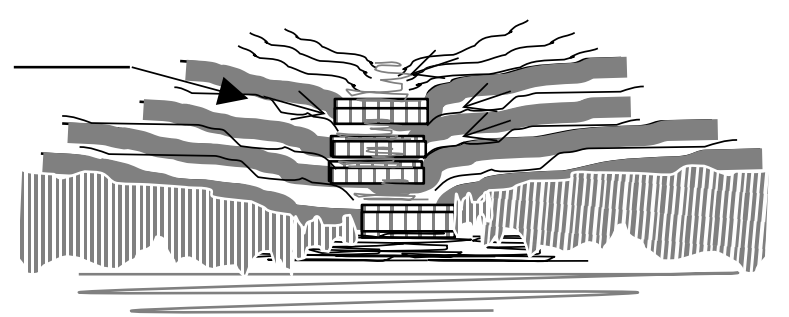

Gambar 17. Pembuatan Gully Stabilition dari kayu/bambu

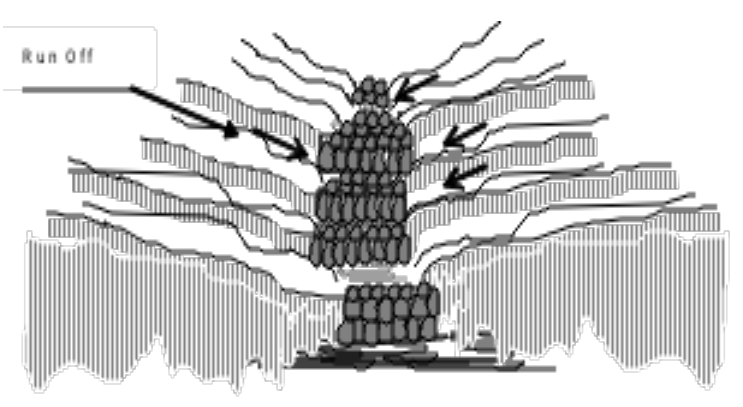

Gambar 18. Pembuatan Gully Stabilition dari pasangan batu kosong

\section{Bangunan Pengendali Erosi}

Usaha untuk memperlambat proses sedimentasi antara lain dengan mengadakan pekerjaan teknik sipil guna mengendalikan gerakannya menuju bagian sungai dibagian hilirnya. Adapun pekerjaannya adalah berupa pembangun an bendungan penahan (check dam, bendung pengatur serta pekerjaam norma lisasi alur sungai (chenne/ work) dan pekerjaan pengendalian erosi di lereng-lereng pegunungan ( hill side work).

Kegiatan yang biasa dilakukan dalam rangka konservasi lahan antara lain dengan cara membangun sederet bendung-bendung pengatur yang biasanya dengan konstruksi dari beton, pasangan batu atau bronjong kawat. Selanjutnya disebelah hulu bendung tersebut akan terisi bahan sedimen yang terangkut oleh air dari hulunya, sehingga terbentuklah terap-terap dan proses penurunan dasar alur dapat dicegah.

\section{Desain Tipikal Bendung Penahan (Check Dam)}

Untuk bendung pengatur gerakan sedimen bahannya berbutir halus, mercunya dapat dibuat lebih tipis. Demikian pula dengan sayap-sayapnya di kanan kiri mercu tersebut yang biasanya digunakan sebagai lalu lintas pejalan kaki. Bahan untuk tubuh bendungan disamping beton dan pasangan batu dapat dibuat dari kayu, bronjong kawat tumpukan batu.

Secara umum fungsi dari check dam yaitu :

- Membentuk kemiringan dasar sungai kecil sehingga mencegah erosi vertikal dari dasar sungai.

- Mengatur aliran sungai sedemikian sehingga mencegah erosi dari dasar sungai.

- Menampung pasir dan kerikil untuk mengendalikan dan mengatur jumlah pasir dan kerikil (sedimen) yang dibawa oleh aliran air.

Secara garis besar dimensi dan 
bentuk tipikal dari bangunan Dam Pengatur (Check Dam) adalah sebagai berikut:

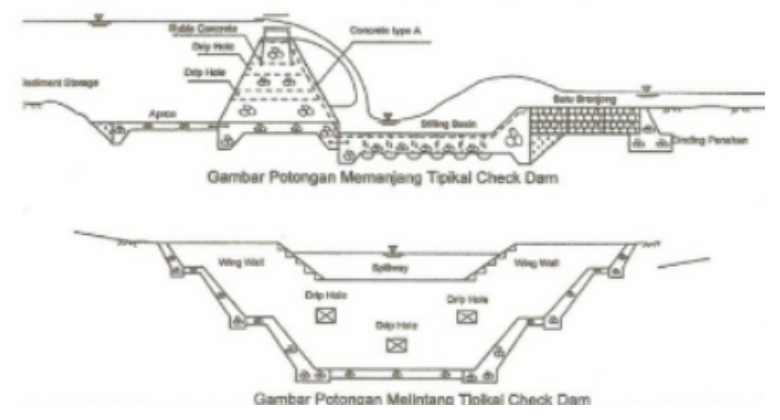

Gambar 19. Detail Bentuk Tipikal Bangunan Check Dam

\section{DAFTAR PUSTAKA}

Agriceli, 2004. Puluhan Daerah Aliran Sungai Kritis. Tempo Interaktif. http://www.tempointeraktif.com/hg/nasio nal/2004/07/09/brk.20040709-32.id.html. [8 Oktober 2004].

Anonim, 1998. "Pedoman Penyusunan Rencana Teknik Lapangan Rehabilitasi Lahan dan Konservasi Tanah DAS", Jakarta : Departemen Kehutanan (Dirjen Reboisasi dan Rehabilitasi Lahan).

Aronoff. 1989. Geographic Information System - A Management Perspective. Ottawa : WDL Publications.

Arsyad, Sitanala. 2000. Konservasi Tanah dan Air. Bogor : IPB Press

Asdak, Chay. 2004. Hidrologi Dan Pengelolaan Daerah Aliran Sungai. Yogyakarta : Gajah Mada University Press.

Badan Pusat Statistik. 2006. Nusa Tenggara Timur Dalam Angka Tahun 2005. Kupang.

Badan Pusat Statistik. 2007. Kabupaten Kupang Dalam Angka 2007. Kupang

Bisri, Mohammad, 2009 Pengelolaan Daerah Aliran Sungai, Malang : Penerbit Percetakan CV. Asrori

ESRI (Environmental System Research Institute, Inc). 1996. ArcView GIS, The Geographic Information System for Everyone. New York: ESRI.

Executif Summary, Rencana Pembangunan Jangka Menengah Daerah Kota Kupang Tahun 2007-2012
Soemarto, CD. 1999. Hidrologi Teknik Edisi Kedua. Jakarta : Erlangga

Soewarno. 1995. Hidrologi Aplikasi Metode Statistik Untuk Analisa Data Jilid 1. Bandung : Nova.

Sosrodarsono, S dan Takeda K. 1999. Hidrologi Untuk Pengairan. Jakarta : PT. Pradnya Paramita.

Suripin. 2004. Pelestarian Sumberdaya Tanah Dan Air. Yogyakarta : ANDI

Sudjarwadi, 1987/1988 Sumber Daya Air, Jogyakarta : Proyek Pengembangan Pusat Fasilitas Bersama antar Universitas (Bank Dunia XVII ) Universitas Gajah Mada.

Tarboton, David. 2000. Distributed Modeling in Hydrology using Digital Data and Geographic Information System. Utah State

University. http://www.engineering.usu.edu.dtarb

Trie M. Sunaryo, Tjoek Waluyo, Aris Harnanto, 2004 Pengelolaan Sumber Daya Air, Konsep \& Penerapannya, Malang, Penerbit Bayu Media Publising

Undang Undang RI No. 7 Tahun 2004 tentang Sumber Daya Air. Pustaka Widyatama. Yogyakarta. 
